\title{
An Online Outpatient Database System: A Case Study of General Hospital, Minna
}

\author{
Opeyemi A. Abisoye1, Blessing 0. Abisoye², Blessing Ele Ojonuba1 \\ ${ }^{1}$ Department of Computer Science, Federal University of Technology, Minna, Nigeria \\ ${ }^{2}$ Information Technology Services (ITS), Federal University of Technology, Minna, Nigeria \\ Email: opeglo@yahoo.com.au, o.abisoye@futminna.edu.ng, blesutunde@yahoo.com, \\ b.abisoye@futminna.edu.ng, blessing.ojonuba@st.futminna.edu.ng
}

Received 2 June 2016; accepted 26 July 2016; published 29 July 2016

Copyright (C) 2016 by authors and Scientific Research Publishing Inc.

This work is licensed under the Creative Commons Attribution International License (CC BY). http://creativecommons.org/licenses/by/4.0/

(c) (i) Open Access

\section{Abstract}

Outpatients receive medical treatment without being admitted to a hospital. They are not hospitalized for 24 hours or more but visit hospital, clinic or associated facility for diagnosis or treatment [1]. But the problems of keeping their records for quick access by the management and provision of confidential, secure medical report that facilitates planning and decision making and hence improves medical service delivery are vital issues. This paper explores the challenges of manual outpatient records system for General Hospital, Minna and infers solutions to the current challenges by designing an online outpatient's database system. The main method used for this research work is interview. Two (2) doctors, three (3) nurses on duty and two (2) staff at the record room were interviewed. Fifty (50) sampled outpatient records were collected. The combination of PHP, MYSQL and MACROMIDIA DREAMVEAVER was used to design the webpage and input data. The records were implemented on the designed outpatient management system and the outputs were produced. The finding shows these challenges facing the manual system of inventory management system. Distortion of patient's folder and difficulty in searching a patient's folder, difficulty in relating previous complaint with the new complains because of volume of the folder, slow access to patient diagnosis history during emergency, lack of back up when an information is lost, and preparation of accurate and prompt reports make it become a difficult task as information is difficult to collect from various register. Based on the findings, this paper highlights the possible solutions to the above problems. An online outpatient database system was designed to keep the outpatients records and improve medical service delivery.

\section{Keywords}

Outpatient, Hospital, Medical, Records, Diagnosis, Database 


\section{Introduction}

Hospitals are highly information intensive organizations which spend substantial sums on information management and processing of inpatients and outpatients database system [2]. It naturally follows that technologies that improve the gathering, storage, transmission and processing of information will be useful tools in hospital management [3]. Since late 1950s, health care visionaries have predicted an information technology (IT) revolution within medical care delivery, a revolution that would transform the health care industry [4] [5]. The early pioneers of medical informatics (the study and use of computer and IT in health care.) formulated a vision for literally transforming modern medicine through use of hospital IT systems [6].

In 1991, the institute of medicines committee on improving the patient (both outpatient and inpatient) record stated a standard use of IT in health care in 2001 [7]. Most hospitals like General Hospital Minna keep and update their paper based medical records after introducing an electronic medical record or database system for outpatient. There should be improvement in the hospital care outcome and care management, reduction of medical errors and increases in both administrative efficiency and patient satisfaction [8].

At the General Hospital Minna, it is suggested that online outpatient database system should be adopted so that outpatient will not be waiting unnecessarily for cards to be found before they could be attended to. Getting access to all their past medical history can be a time consuming, frustrating, confusing process.

It is necessary for outpatient to have an ideal secured database record management system based on details of medical records [9]. The absence of computerized medical records in most hospitals in the country makes this ideal unattainable [10]. Although computerized medical records to be access online are forgone issues in developed countries, many hospitals are yet to embrace it in Nigeria [11]. This research seeks to practice the management of online access of outpatient records electronically so as to provide an easy access to critical patient records and also provide logical continuation to regional health network by allowing distant sites to collaborate and exchange their data for specific research via the computer system. This case study focuses on outpatient scheduling, by evaluating different appointment scheduling systems as a means to reduce patients' waiting times, to improve the outpatient clinic's utilization, to reduce doctor's overtime and idle time, and to focus on the counter personnel's peak workload as well.

\section{Overview of General Hospital Minna}

General Hospital Minna was established in 1946 in order to provide quality healthcare services. During this period the hospital was controlled by the regional and native authorities as well as missionaries'. The hospital is now controlled by Niger state ministry of health and it serves as medical center for medical internship (houseman-ship) for medical students from other institution. The general Hospital Minna is located at the metropolitan part of Minna the Niger state capital which gives easy access to people around its environment. The hospital is headed by Chief Medical Officer (C.M.O) and is made up of the following specialties and departments;

a) Surgical: pertaining to or involving surgery or surgeons.

b) Medical: relating to the science or practice of medicine. Is the applied science or practice of the diagnosis, treatment and prevention of disease? It encompasses a variety of health care practice evolved to maintain and restore health by the prevention and treatment of illness in human beings. The word medicine is derived from the Latin arts medical, meaning the art of healing.

c) Pediatrics: the branch of medical dealing with children and their diseases.

d) Gynecologist: is the medical practice dealing with the health of the female reproductive system.

e) Dental: of or relating to the teeth. The dental section deals with general dental illness and the overall dental health of patient. This section also develop initial treatment plan and refers to specialist when more specialized treatment is required.

f) Ophthalmic: pertaining to eye and its diseases.

g) Nursing: the protection, promotion, and optimization of health and abilities, prevention of illness and injury.

h) Pharmacy: the science or practice of the preparation and dispensing of medicinal drugs. The pharmaceutical section gives out the prescribe drugs to patients. This implies that a patient's must first visit the doctor for complains before coming to this section to obtain drugs needed for the cure of illness.

i) Laboratory: a room or a building equipped for scientific research, or teaching, or for the manufacture of drugs or chemicals. Is section is responsible for conducting laboratory tests on patients e.g. blood and urine test. 
For a test to be conducted on a patient, it has to be requested by the doctor.

j) Medical records: contain sensitive information and increasing computerization and other policy. This section form an essential part of the patient's present and future health care. It provide the written collection of information about a patient's health and treatment, which are essential for the present and continuing care of the patient.

k) Maintenance: is the process of keeping or preserving something in good condition.

l) Social welfare: governmental provision of economic assistance to persons in need, which is the well being of the entire society.

m) X-ray: electromagnetic radiation of short wavelength produced when high speed electrons strike a solid target.

n) Public health: is the health service to improve and protect community health, sanitation, immunization and prevent medicine.

o) Admin: an abbreviation of system operator. Hospital administration is the management of the hospital as business. It is made up of medical and health service managers.

It is evident that the number of patient being treated is on the increase, therefore for a speeding and easier handling of patients medical records at this rate, requires some technology which brought about the need to computerize the patients records and medical history electronically in order to enhance operation effectively.

\section{Outpatients Department}

The Outpatients Department is as old as the hospital itself. It consist of General Out-Patient unit (GOPU), Emergency Out-Patient unit (EOPU), National Health Insurance Scheme (NHIS) clinic and Intensive Care Unit (ICU)

The department has 1 consulting room, 1 resting room for doctors, a ward, 1 nurse changing room, an injection room, and an attached casualty theater.

\section{Functions of Outpatients Department}

As the name imply, the department performs the following function:

1) Receive and attend to all new and old patients coming to the hospital in emergency.

2) Admit emergency patients and observe for 24 - 48 hrs and transfer to the ward, or discharge as the case may be.

3) Facilitate the admission of all new patients to respective wards.

4) Coordinate and supervise activities of the hospital during afternoon and night shift duties.

5) Write detailed report of admissions, discharge and any other directive during shift duties.

\section{Statement of the Problem}

The General Hospital Minna outpatient record exhibited a lot of difficulties in the system which is manual and is based on paper cards to collect an outpatient record. So it needed Information Technology (IT) based solution, an evaluation of alternative appointment systems to reduce waiting times and underutilization of an outpatient database system in the hospital. Some of the problems are stated below:

1) Data is stored in a way which makes it difficult for the management to retrieve useful information.

2) Enquiries about the patients record are sometimes difficult to deal with as patient's record are not stored in a form that is easily accessible.

3) Problems were encountered is the time-consuming nature of the manual of the patients lists and retrieval of patient file for various reason from the existing record system.

4) The hospital does not have back-up of medical records in the case of natural disaster for example flood, fire-outbreak.

5) Missing some or most of the patient's records.

6) Patients information is usually mixed up while carrying files from one point to another.

\section{Aim and Objectives}

Aim: To design an online outpatient database system for medical unit of General Hospital Minna to provide easy access to outpatient record.

Objectives are the following:

1) To explore the functions of medical unit and investigate the services being rendered to the outpatient. 
2) To examine the challenges of the service being rendered to the outpatient records manually and the possible solution.

3) To design an online outpatient database system to solve the problems through the use of Dreamweaver and PHP programming packages.

4) To implement outpatient records on the online database management system and make recommendations based on the research made from the study of medical records.

\section{Significance of the Study}

This large scale sharing of medical records via network connections has the potential to bring us numerous benefits. Online outpatient record will be separated from the inpatient at the hospital. This study would be found useful for the General Hospital Minna because it will help to address the problem of security; privacy and confidentiality of patient health records. It also helps to check the delay, error, inconsistencies in medical records and timely access to historical records all of which had a significant impact on the quality of the hospital. The implementation of online hospital database system is vital to the provision of quality care, as well as adequate management of scares resources and productivity.

\section{Research Methodology}

Survey method of interview was used. I had one to one interview with two (2) doctors, three (3) nurses on duty and two (2) staff at the record room. Fifty (50) sampled outpatient records were collected. This made it possible for me to gain an insight into the daily activities of the various staff, thus provide a good launch pad for the design of the user interface and interaction model for the software. The records were implemented on the designed outpatient management system and the outputs were produced.

\section{Analysis of the Existing System}

Currently the General Hospital Minna, electronic system of operation as not been implemented in any of the unit of the hospital. The step by step activities carried out at the Hospital for registration and consultation includes the following:

1) The patient has to be registered with the Hospital before he/she can visit the Hospital for consultation. The registration process involves filling the medical form by both the patient and Doctor. Information filled by the patient is necessary personal detail about the patient, while those filled by the Doctor are the result obtained from the test conducted on the patient.

2) After the forms have been completed they are submitted to the staff in charge of the record room. Then a folder is created for the patient and he is given a Hospital card.

3) Whenever the patient is visiting the Hospital for consultation he/she present the card which contains information like name, address, folder name and the passport of the patient. Then the patient is sent to see the doctor.

4) The patient meets the doctor for consultation. The doctor view the necessary information needed to conclude his diagnosis and aid prescription given to the patient.

5) Then the patient is sent to the appropriate unit depending on the diagnosis and prescription.

\section{Problem of the Existing System}

Some of the problems encountered or that are likely to be encounter as a result of the manual system adopted at the Hospital are as follow:

a) Distortion of patient's folder.

b) Difficulty in searching a patient's folder.

c) Difficulty in relating previous complaint with the new complains because of volume of the folder.

d) Misplacement or mix up of content of patient's folder.

e) Congestion of record room.

f) Lack of back up for data could lead to loss of entire information kept in the Hospital, in the event of disaster.

g) Patient's are delayed or prevented from meeting the doctor, if the Hospital card could not be presented at record room. 
h) Slow access to patient diagnosis history during emergency can lead to ineffective and slow attention to be given to the patients.

i) Preparation of accurate and prompt reports, this becomes a difficult task as information is difficult to collect from various registers

j) Lack of immediate information storage; the information generated by various transactions takes time and efforts to be stored at right place.

\section{Possible Solutions}

\subsection{Improved Manual System}

One of the alternative solutions is the improvement of the manual system. Whatever we use automated methods, can be done manually [4]. But the question arises how to perform thing manually in a sound manner. The following are some suggestions, which can be useful in manual system.

I. More sophisticated register maintenance for various patients' information, Doctor Diary, nurses roster and so on can be maintained at central place.

II. Adequate staff may be maintaining so that updating are made at the very moment at the same time.

III. Eligible person for work should be made responsible so that a better efficiency could be achieved. This needs a lot of work force [12].

\subsection{Batch System}

Another alternative solution is the computer based batch system for maintaining the information regarding purchase details, customers and employees [13] [14]. A batch system refers to a system in which data is processed in periodical bases [15] [16]. The batch system is able to achieve most of the goals and sub goals. But a batch system data is processed in sequential basis, therefore batch system is not suggested.

\subsection{Online System}

This system provides online storage/updating and retrieval facility [17]. This system promises very less or no paper work and also provides help for Doctors and operational staff. In this system everything is stored electronically so very less amount of paper work is required and information can be retrieved very easily without searching here and there into registers. This online outpatient database system is the proposed system.

\subsection{Proposed System}

a) Data retrieval module

This provides quick access to patient record through the use of identification number. It reduces the stress and time needed to retrieve patient's folder. If the folder is to be retrieving manually, the time, energy and importantly efficiency of service is degraded.

b) Drag prescription module

It allows doctors to prescribe drug to patient. The prescribed drug will be prescribed attached to the patients profile automatically. It allows the doctor or any other doctor in future to view the prescribed drug and the illness they were prescribed for.

c) Laboratory test require and report module

This allows laboratory test and result to be properly documented. It is use by the doctor to request at a test be performed on a patient. After the test have been conducted is then attach to the patient profile.

d) Security module

This modules is use to prevent unauthorized user from performing certain task e.g. diagnosis, updating nurses roster and so on.

e) Online complain, diagnose and prescription module

This module allow patient to complain online and receive their diagnosis and prescription that has been made by the doctor base on their complain.

It is important to note that Figure 1 does not include all the files that make up this application. It is merely a representation of the structure of the application. A representation of the system's basic operations as an end user sees it can best be captured with the use of a Use-Case diagram. 


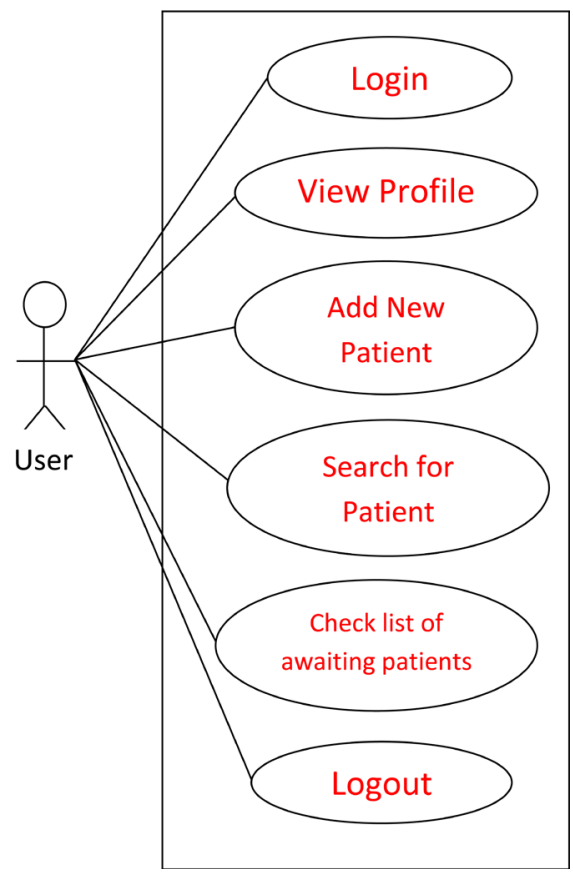

Figure 1. Schematic representation of the proposed system.

\subsection{Advantages of the Proposed System}

a) Provide quick access to patient record,

b) Help to reduce drug abuse by providing online complain,

Diagnosis and prescription which allow patient to forward their heath issues without necessarily visiting the clinic,

c) Allow regular back up which can be use to bring the database to last healthy state when there is disaster or hardware failure,

e) Enhances information integrity, reduce transcription errors, and reduces duplication of information.

\subsection{Chosen Web Application Technologies}

The combination of MySQL and Adobe Dreamweaver was used for this research because they are open source which implies that they are cheap to get since one just need to download them from net. Adobe Dreamweaver is used by web designers and webmasters for novice and professionals to create and dynamic websites while MySQL is chosen as the database management system because of its efficient data handling.

\section{Data Collection}

One to one interview with three Doctors, seven nurses on duty and ten patients at the record room was conducted. Here are some questions that were asked.

\section{Research Questions}

Nurse Section

1) How do you create records for new patient?

2) How do you check for existing patient data?

3) How do you queue them up for Doctor's awaiting list?

4) How do you delete from the awaiting list the patient the Doctors has attended to?

5) What are the major problem being encountered?

Doctors Section

1) How do you get the compliant of the patient in the awaiting list? 
2) How do you diagnose the patient in the awaiting list?

3) What are the major problem being encountered?

Answers

1) By creating file that contains the patient data,

2) By retrieving the created file,

3) By creating a list of the patient arrival time,

4) By asking her questions about the condition of her health,

5) Time Consumption,

6) By using mental medical inference rules and relate it with the past record,

7) Remove the patient attended list from the awaiting list,

8) Diagnosis is not easy and straightforward without the computer based inference rules?

\section{Results}

Figure 2 shows the staff login page with username and password. While in Figure 3, Nurse Queen by Name has successfully logged on; this Nurse is responsible for creating records for new patients as shown in Figure 4 and checking for existing patients and queuing them up for the Doctor to attend to them. The illustration in Figure 4 asks for the patient's personal information

If the patient does not exist an action will be taken, while the physician is responsible for diagnosing them. The patient is removed from the waiting list after the Doctor confirms the diagnosis. The profile can be updated in case of any changes in the staff information. Figure 5 is a view of a new record added successful.

The administrator can search for the patient either by name or ID using Figure 6 from the comprehensive list of awaiting patients in Figure 7.

The Nurse Queen has successfully searched for a patient "Iko Mercy" the ID in front of the passport help to differentiate between two Iko Mercy should in a case arise. The patients ID is being generated automatically.

The information about the patients is uploaded to the doctor Ako on duty. Then he double clicks on the patient ID to get all the information to diagnose one after the other according to how they came as shown in Figure 8. The Doctor proceeded by clicking on diagnose in Figure 9 the patients form; to record complain about his or her health or go for test.

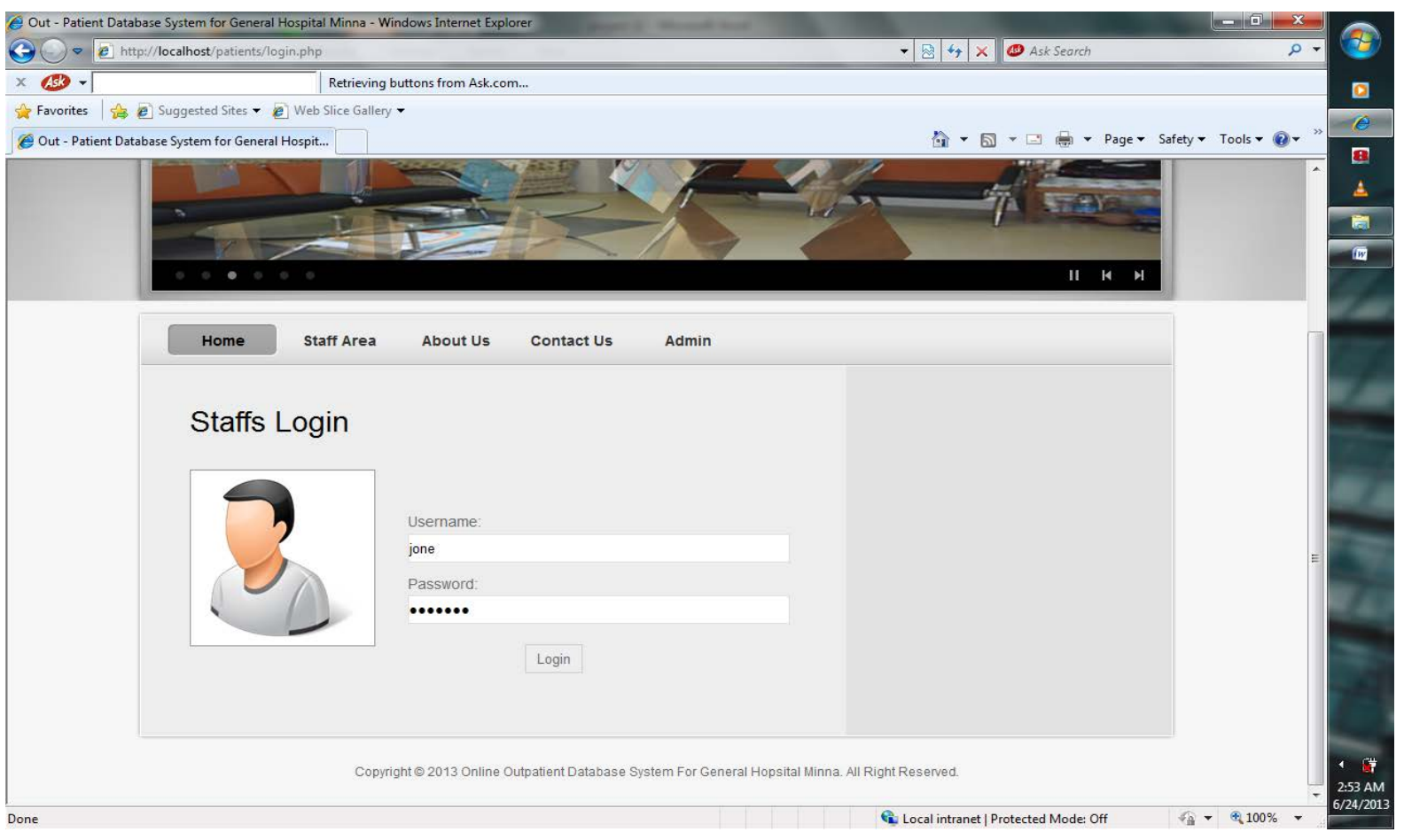

Figure 2. Staff login. 


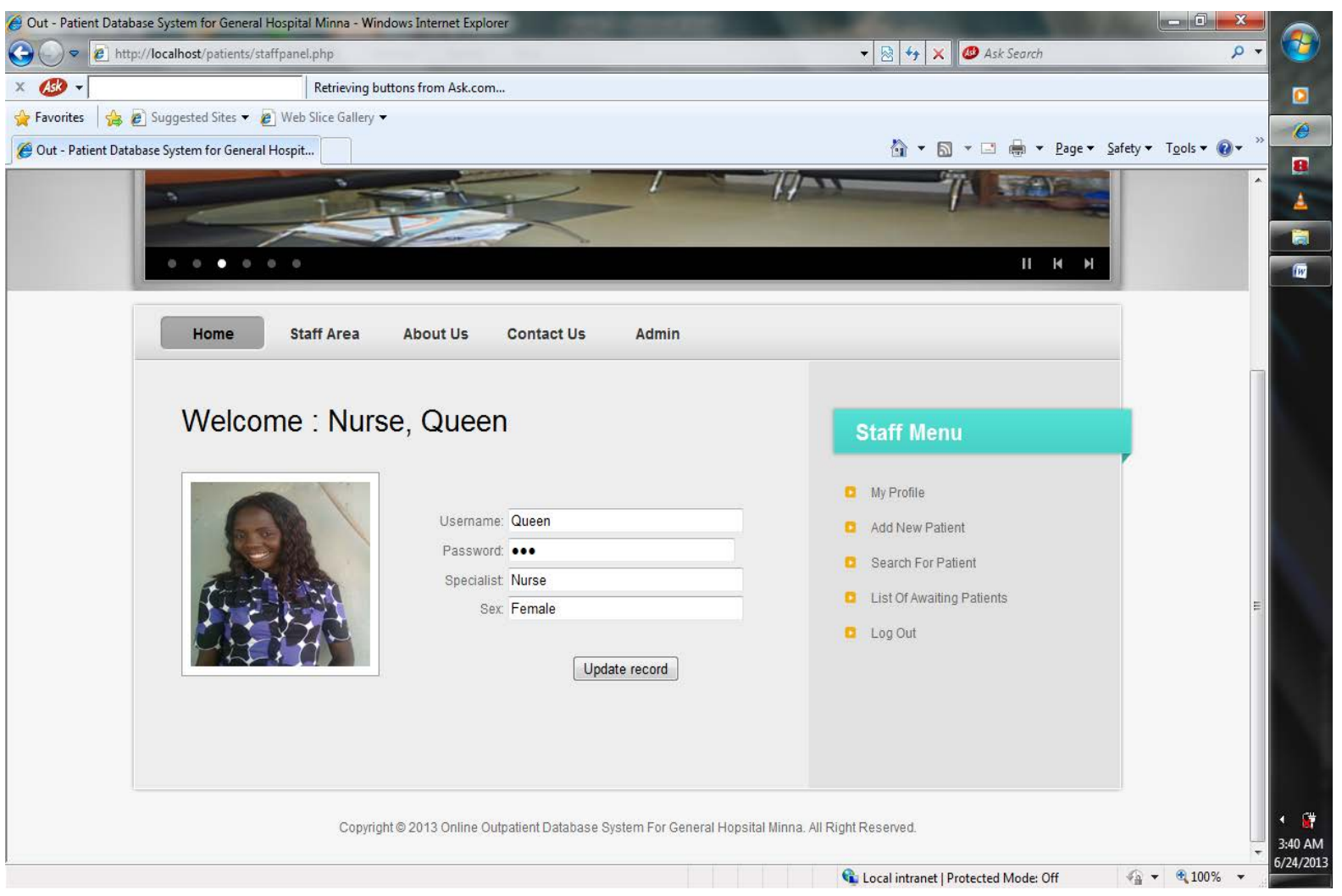

Figure 3. Default view for an authenticated nurse profile.

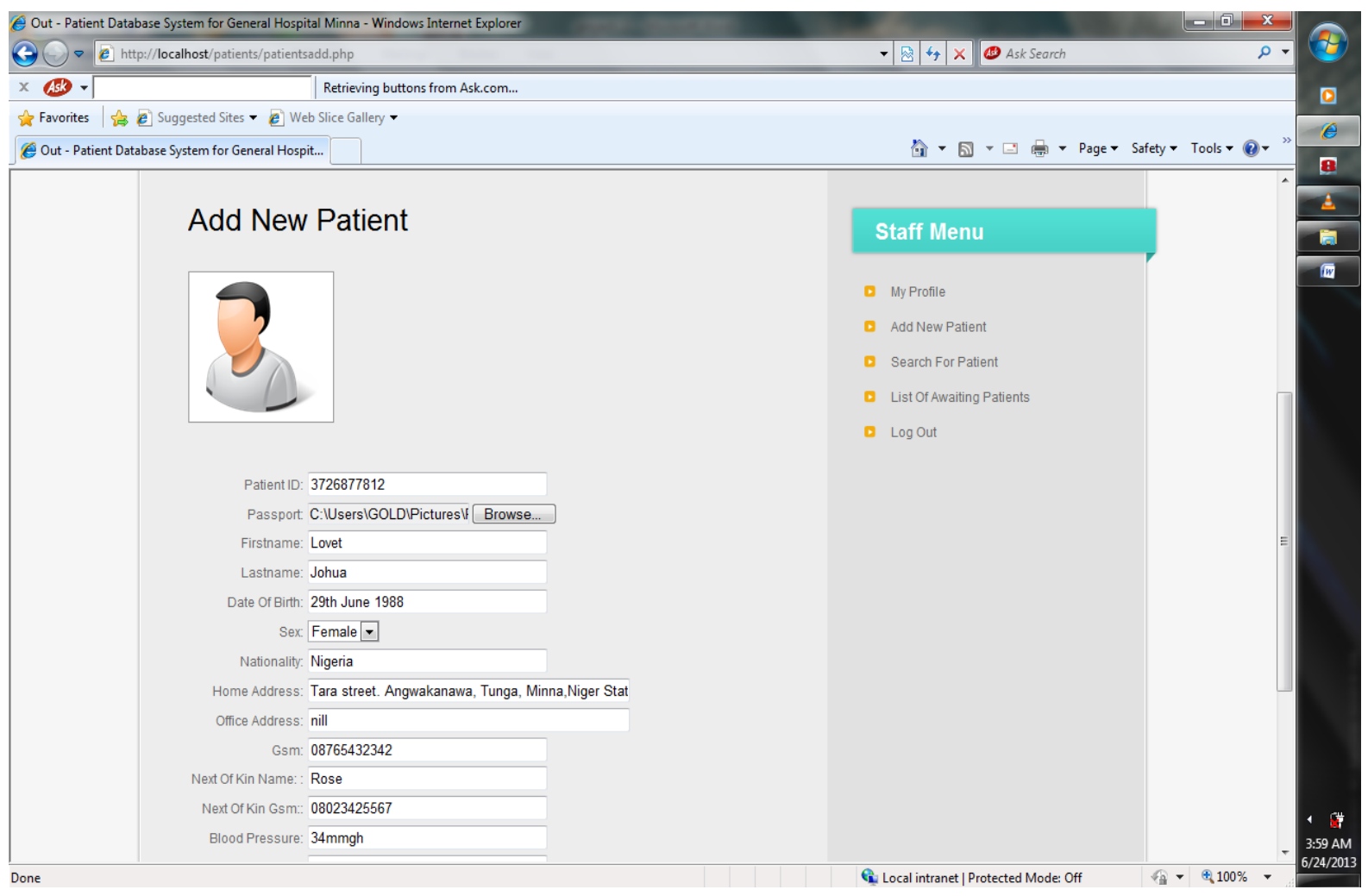

Figure 4. Nurse registering a new patient. 


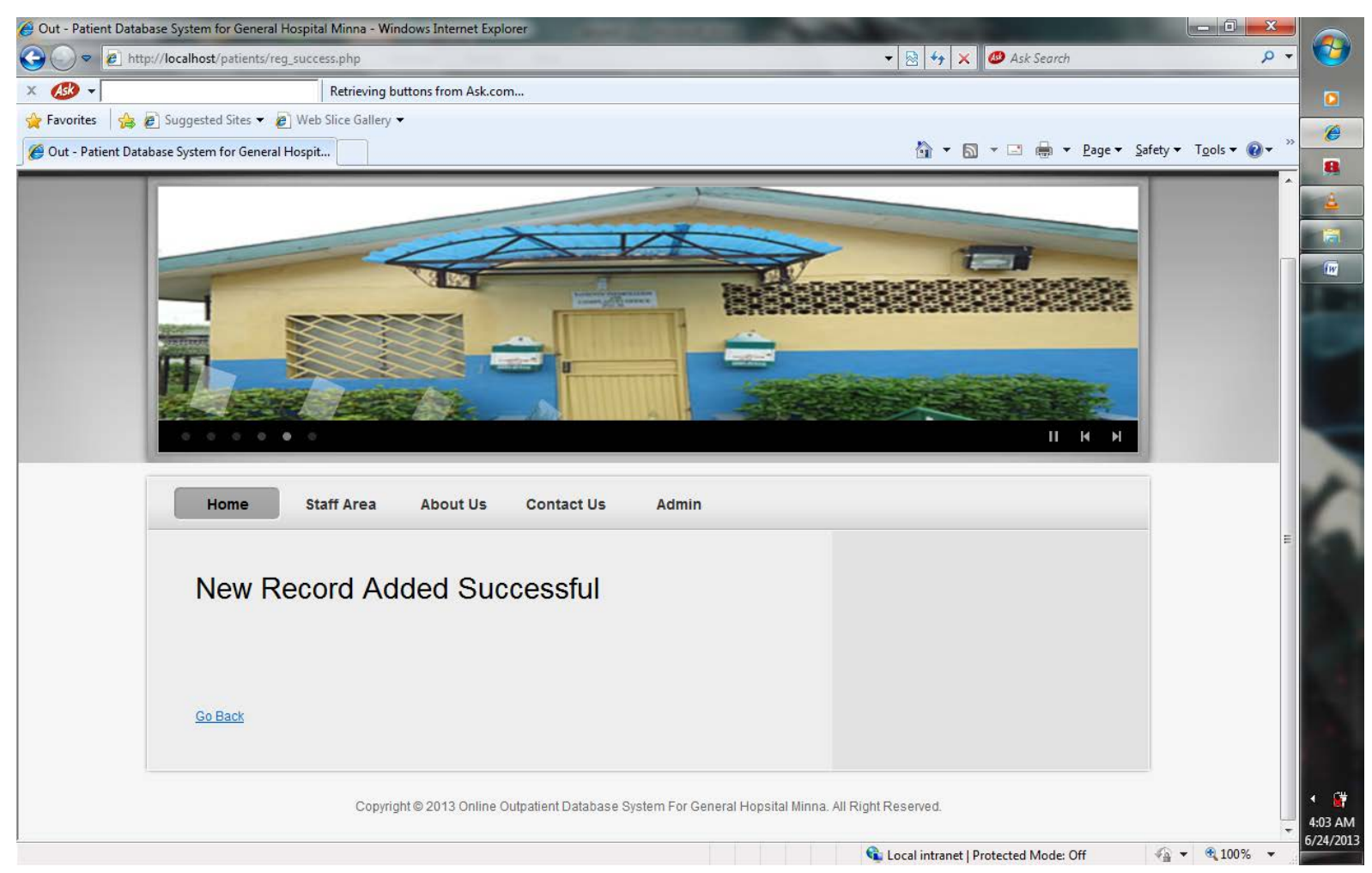

Figure 5. A new record added.

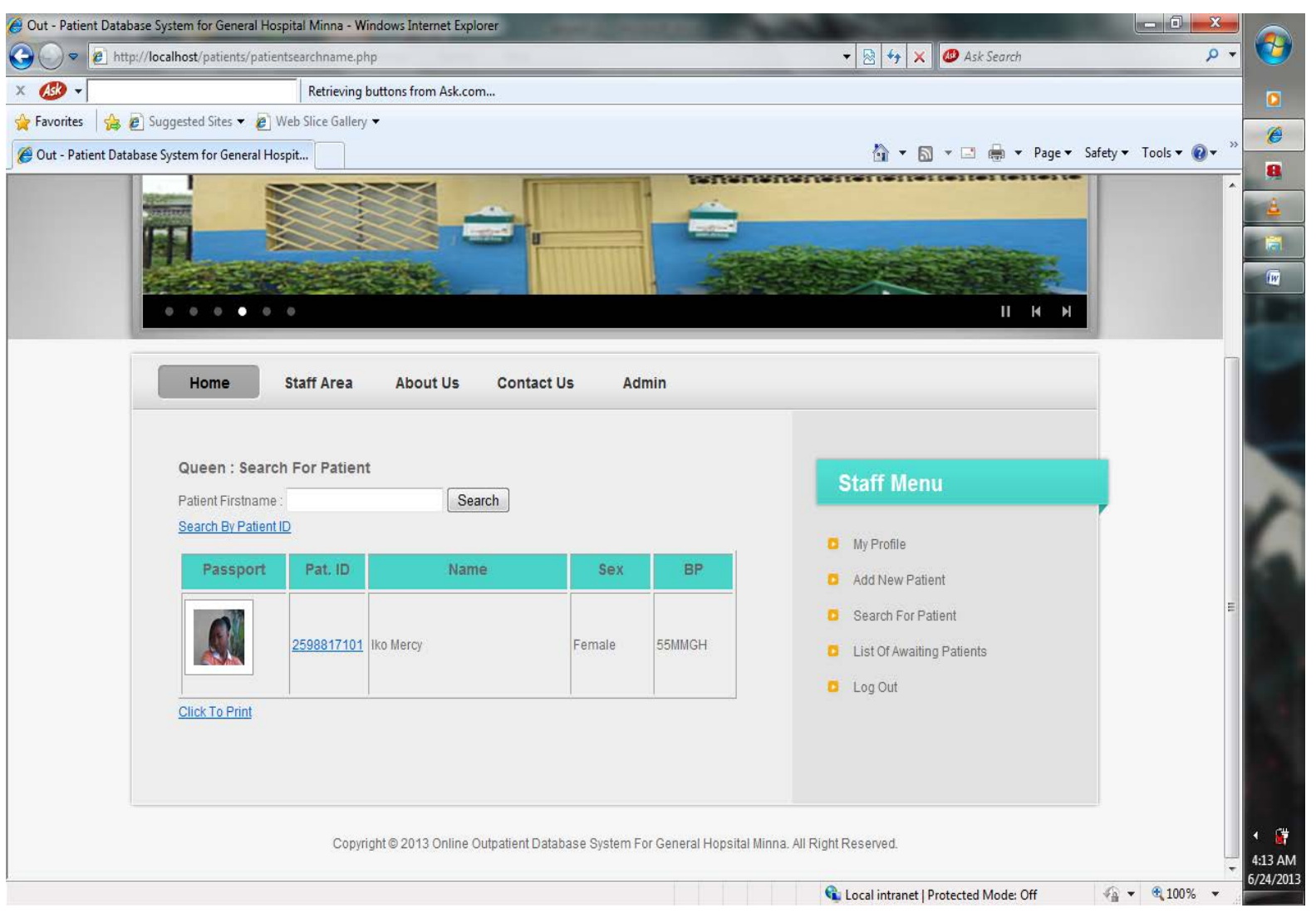

Figure 6. Searched patient 


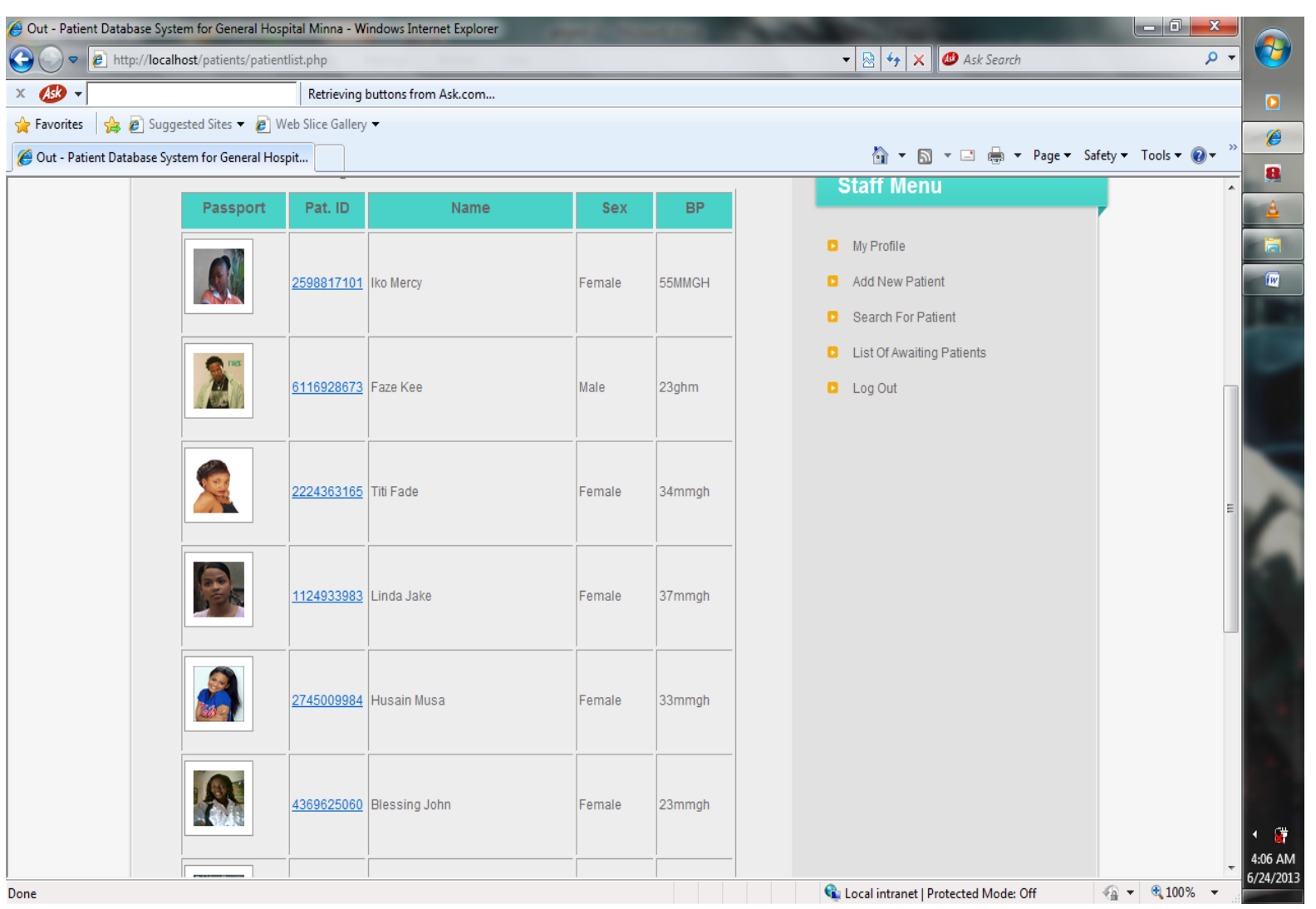

Figure 7. List of awaiting patients.

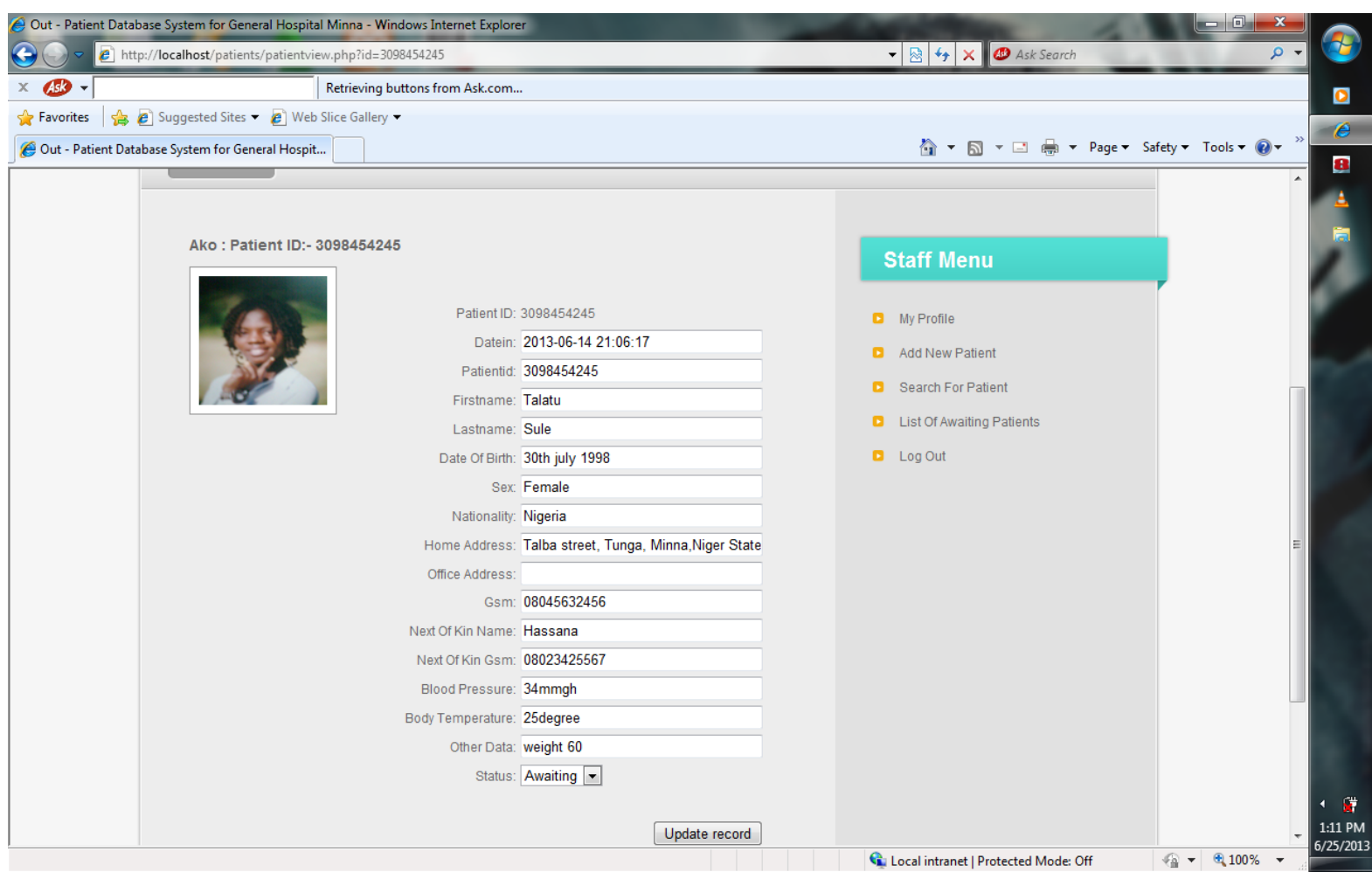

Figure 8. Search patient by ID. 


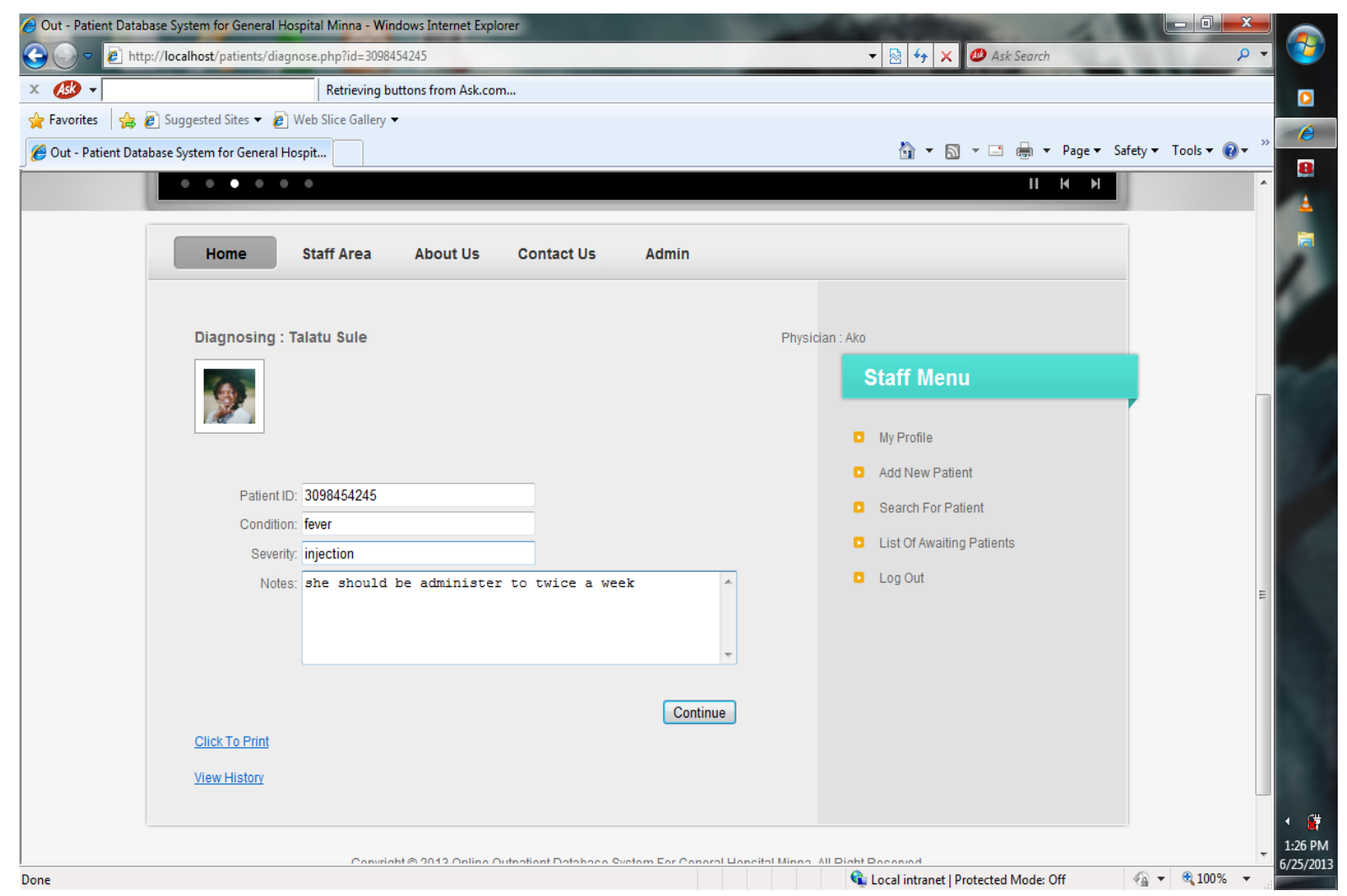

Figure 9. Diagnosing Talatu Sule.

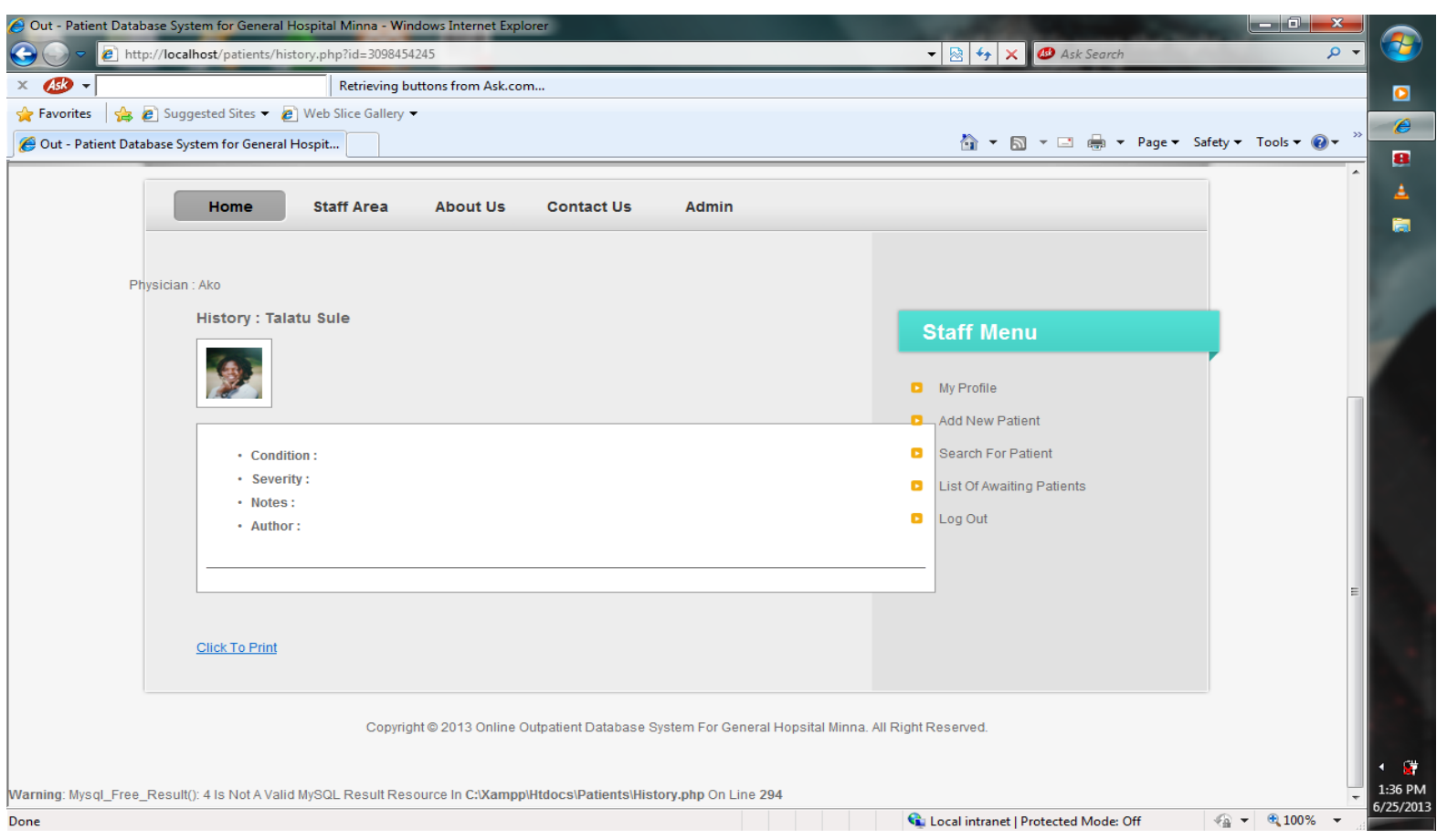

Figure 10. History of the patients.

The physician Ako attended to Talatu Sule by asking her questions about the condition of her health.

Doctor Ako has checked patient Talatu Sule. He then checks the history of the patient in Figure 10 and saves 
it or prints it out.

\section{Conclusion and Recommendation}

In conclusion, the online system saves time and money. It improves the operations on outpatient records and gives the power to access and manipulate vital information quickly and efficiently. The difficulties of delay of manual system, unavailability of backup of data and also security of patient's information have been minimized. The new system ensures data authenticity, accuracy, and availability any time and in a fast and efficient way. The online outpatient database system is therefore a great advantage to General Hospital Minna most especially the Medical Record Department which till date operates a manual system of record keeping. This online outpatient database system is now recommended for the hospital and for other medical record department in various hospitals.

\section{References}

[1] Weinberger, M., Oddone, E.Z. and Henderson, W.G. (1996) Does Increased Access to Primary Care Reduce Hospital Readmissions? New England Journal of Medicine, 334, 1441-1447. http://dx.doi.org/10.1056/NEJM199605303342206

[2] Gray, J.N. (1978) Notes on Data Base Operating Systems. In: Bayer, R., Graham, R.M. and Seegmüller, G., Eds., Operating Systems, Springer, Berlin Heidelberg, 393-481. http://dx.doi.org/10.1007/3-540-08755-9 9

[3] Crane, R.M. and Raymond, B. (2003) Fulfilling the Potential of Clinical Information Systems. The Permanente Journal, 7, 62-67.

[4] Bainbridge, L. (1983) Ironies of Automation. Automatica, 19, 775-779. http://dx.doi.org/10.1016/0005-1098(83)90046-8

[5] Yeon, N., Lee, T. and Jang, H. (2010) Outpatients Appointment Scheduling with Multi-Doctor Sharing Resources. Proceedings of the 2010 Winter Simulation Conference (WSC), 3318-3329.

[6] Shortliffe, E.H. (1999) The Evolution of Electronic Medical Records. Academic Medicine, 74, 414-419. http://dx.doi.org/10.1097/00001888-199904000-00038

[7] Davenport, T.H. (2013) Process Innovation: Reengineering Work through Information Technology. Harvard Business Press.

[8] Senko, M.E., Altman, E.B., Astrahan, M.M. and Fehder, P.L. (1973) Data Structures and Accessing in Data-Base Systems, I: Evolution of Information Systems. IBM Systems Journal, 12, 30-44. http://dx.doi.org/10.1147/sj.121.0030

[9] Shortell, S.M., Jones, R.H., Rademaker, A.W., et al. (2000) Assessing the Impact of Total Quality Management and Organizational Culture on Multiple Outcomes of Care for Coronary Artery Bypass Graft Surgery Patients. Medical Care, 38, 207-217. http://dx.doi.org/10.1097/00005650-200002000-00010

[10] Adeleke, I.T., Asiru, M.A., Oweghoro, B.M., Jimoh, A.B. and Ndana, A.M. (2015) Computer and Internet Use among Tertiary Healthcare Providers and Trainees in a Nigerian Public Hospital. American Journal of Health Research, 3, 1-10.

[11] Hotho, A., Jäschke, R., Schmitz, C. and Stumme, G. (2006) Information Retrieval in Folksonomies: Search and Ranking. 2006 Proceedings of the 3rd European Semantic Web Conference, Budva, Montenegro, 11-14 June 2006, 411-426. http://dx.doi.org/10.1007/11762256_31

[12] Manalang, M.A.P. (2006) Tutorial and Online Examination System. Doctoral Dissertation, University of the Philippines, Manila.

[13] Allen, F.H., Bellard, S.D.B.M., Brice, M.D., et al. (1979) The Cambridge Crystallographic Data Centre: Computer-Based Search, Retrieval, Analysis and Display of Information. Acta Crystallographica Section B: Structural Crystallography and Crystal Chemistry, 35, 2331-2339.

[14] Pizzi, L.T., Howell, J.B., Deshmukh, A., Cohen, H. and Nash, D.B. (2004) Clinical Information Management Systems: An Emerging Data Technology for Inpatient Pharmacies. American Journal of Health System Pharmacy, 61, 76-80.

[15] Schewe, C.D. (1976) The Management Information System User: An Exploratory Behavioral Analysis. Academy of Management Journal, 19, 577-590. http://dx.doi.org/10.2307/255792

[16] Dexter, P.R., Perkins, S., Overhage, J.M., Maharry, K., Kohler, R.B. and McDonald, C.J. (2001) A Computerized Reminder System to Increase the Use of Preventive Care for Hospitalized Patients. New England Journal of Medicine, 345, 965-970. http://dx.doi.org/10.1056/NEJMsa010181

[17] Idowu, B., Adagunodo, R. and Adedoyin, R. (2006) Information Technology Infusion Model for Health Sector in a Developing Country: Nigeria as a Case. Technology and Health Care, 14, 69-77. 


\section{Submit or recommend next manuscript to SCIRP and we will provide best service for you:}

Accepting pre-submission inquiries through Email, Facebook, LinkedIn, Twitter, etc.

A wide selection of journals (inclusive of 9 subjects, more than 200 journals)

Providing 24-hour high-quality service

User-friendly online submission system

Fair and swift peer-review system

Efficient typesetting and proofreading procedure

Display of the result of downloads and visits, as well as the number of cited articles

Maximum dissemination of your research work

Submit your manuscript at: http://papersubmission.scirp.org/ 